\title{
Mechanism of Activation of Acyl-CoA Substrates by Medium Chain Acyl-CoA Dehydrogenase: Interaction of the Thioester Carbonyl with the Flavin Adenine Dinucleotide Ribityl Side Chain ${ }^{\dagger}$
}

\author{
Stefan Engst, ${ }^{\ddagger}$ Petra Vock,$‡$ Ming Wang, ${ }^{\S}$ Jung-Ja P. Kim,${ }^{\S}$ and Sandro Ghisla*, ${ }^{*}$ \\ Faculty of Biology, University of Konstanz, P.O. Box 5560-M644, D-78434 Konstanz, Germany, and \\ Department of Biochemistry, Medical College of Wisconsin, Milwaukee, Wisconsin 53226
}

\begin{abstract}
The flavin adenine dinucleotide (FAD) cofactor of pig kidney medium-chain specific acylcoenzyme A (CoA) dehydrogenase (MCADH) has been replaced by ribityl-3'-deoxy-FAD and ribityl2'-deoxy-FAD. 3'-Deoxy-FAD-MCADH has properties very similar to those of native MCADH, indicating that the FAD-ribityl side-chain 3'-OH group does not play any particular role in cofactor binding or catalysis. 2'-Deoxy-FAD-MCADH was characterized using the natural substrate $\mathrm{C}_{8} \mathrm{CoA}$ as well as various substrate and transition-state analogues. Substrate dehydrogenation in $2^{\prime}$-deoxy-FAD-MCADH is $\approx 1.5$ $\times 10^{7}$-fold slower than that of native MCADH, indicating that disruption of the hydrogen bond between $2^{\prime}-\mathrm{OH}$ and substrate thioester carbonyl leads to a substantial transition-state destabilization equivalent to $\approx 38 \mathrm{~kJ} \mathrm{~mol}^{-1}$. The $\alpha \mathrm{C}-\mathrm{H}$ microscopic $\mathrm{p} K_{\mathrm{a}}$ of the substrate analogue $3 \mathrm{~S}-\mathrm{C}_{8} \mathrm{CoA}$, which undergoes $\alpha$-deprotonation on binding to $\mathrm{MCADH}$, is lowered from $\approx 16$ in the free state to $\approx 11( \pm 0.5)$ when bound to $2^{\prime}$-deoxy-FAD-MCADH. This compares with a decrease of the same $\mathrm{p} K_{\mathrm{a}}$ to $\approx 5$ in the complex with unmodified hwtMCADH, which corresponds to a $\mathrm{p} K$ shift of $\approx 11 \mathrm{p} K$ units, i.e., $\approx 65 \mathrm{~kJ} \mathrm{~mol}^{-1}$ [Vock, P., Engst, S., Eder, M., and Ghisla, S. (1998) Biochemistry 37, 1848-1860]. The difference of this effect of $\approx 6 \mathrm{pK}$ units $\left(\approx 35 \mathrm{~kJ} \mathrm{~mol}^{-1}\right)$ between MCADH and $2^{\prime}$-deoxy-FAD-MCADH is taken as the level of stabilization of the substrate carbanionic species caused by the interaction with the FAD-2'-OH. This energetic parameter derived from the kinetic experiments (stabilization of transition state) is in agreement with those obtained from static experiments (lowering of $\alpha \mathrm{C}-\mathrm{H}$ microscopic $\mathrm{p} K_{\mathrm{a}}$ of analogue, i.e., stabilization of anionic transition-state analogue). The contributions of the two single H-bonds involved in substrate activation (Glu376amide- $\mathrm{N}-\mathrm{H}$ and ribityl-2'-OH) thus appear to behave additively toward the total effect. The crystal structures of native pMCADH and of 2'-deoxy-FAD-MCADH complexed with octanoyl-CoA/octenoyl-CoA show unambiguously that the FAD cofactor and the substrate/product bind in an identical fashion, implying that the observed effects are mainly due to (the absence of) the FAD-ribityl-2'-OH hydrogen bond. The large energy associated with the 2'-OH hydrogen bond interaction is interpreted as resulting from the changes in charge and the increased hydrophobicity induced by binding of lipophilic substrate. This is the first example demonstrating the direct involvement of a flavin cofactor side chain in catalysis.
\end{abstract}

The acyl-CoA dehydrogenases constitute a family of enzymes that act in the desaturation of CoA-conjugated fatty acids $(1,2)$. This family belongs to the large class of flavindependent dehydrogenases (3-5). Most members of this class catalyze the cleavage of one kinetically stable $\mathrm{C}-\mathrm{H}$ bond and one labile $\mathrm{X}-\mathrm{H}$ bond, where $\mathrm{X}=\mathrm{N}, \mathrm{O}$, or $\mathrm{S}$. In contrast, acyl-CoA dehydrogenases and a few other enzymes such as dihydroorotate dehydrogenase (6) catalyze the

$\dagger$ This work was supported by a grant from the Deutsche Forschungsgemeinschaft (Gh 2/4-7, Gh 2/6-1 to S.G.) and from the U.S. Public Health Service grant (GM29076 to J-J.P.K.). A preliminary report of this work was presented at the Tenth International Symposium on Flavins and Flavoproteins, 1990, in Como, Italy.

* Correspondence to S. Ghisla, Fakultät Biologie, Universität Konstanz, Postfach 5560, M644, D-78434 Konstanz, Germany. Tel. +497531 882291. Fax +497531 884161. E-mail: Sandro.Ghisla@unikonstanz.de.

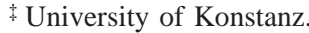

$\S$ Medical College of Wisconsin breakage of two kinetically stable $\mathrm{C}-\mathrm{H}$ bonds of their corresponding substrates. One of these bonds, $\alpha \mathrm{C}-\mathrm{H}$ in Scheme 1, requires chemical activation by a flanking functional group. In the medium-chain acyl-CoA dehydrogenase-catalyzed reaction cleavage of this bond occurs via abstraction of the hydrogen as a $\mathrm{H}^{+}$by Glu376- $\mathrm{COO}^{-}$, the catalytically essential base (7-9). The $\beta \mathrm{C}-\mathrm{H}$ is expelled concomitantly as a hydride which, in turn, is transferred to the oxidized flavin position $\mathrm{N}(5)(10)$. The two processes are concerted (11) and result in the transfer of two reducing equivalents to the (enzyme-bound) oxidized flavin, thus reducing the flavin. This is referred to as the "reductive halfreaction" and yields fully reduced flavin (3-5) as shown in Scheme 1, a.

In the second process, the "oxidative half-reaction" (Scheme 1, b), the electrons are transferred from the reduced flavin to electron-transferring flavoprotein (ETF), ${ }^{1}$ and from 
Scheme 1: Catalytic Cycle of Acyl-CoA Dehydrogenase ${ }^{a}$

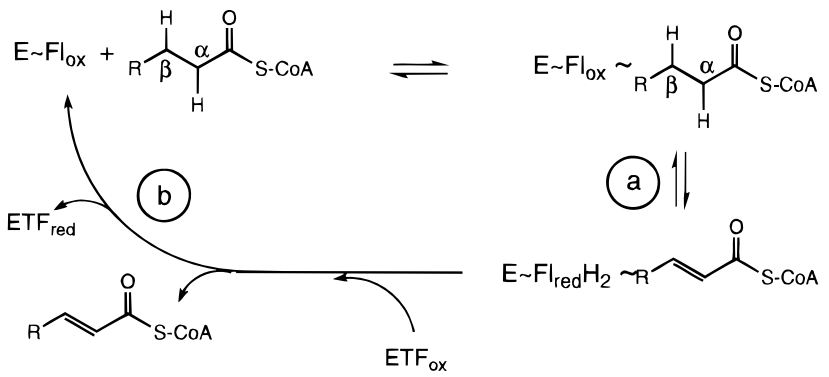

a (a) Represents the reductive and (b) the oxidative "half-reaction". Note that the sequence is not formally balanced for protons.

there funneled into the mitochondrial respiratory chain via ETF-oxidoreductase.

A crucial issue in the dehydrogenation reaction of acylCoA dehydrogenase is the mode and extent of activation of $\alpha \mathrm{C}-\mathrm{H}$. For efficient catalysis, current concepts assume that the microscopic $\mathrm{p} K_{\mathrm{a}}$ values of two partners involved in the transfer of one $\mathrm{H}^{+}$between them have similar values (12, 13). The microscopic $\mathrm{p} K_{\mathrm{a}}$ of $\mathrm{Glu} 376-\mathrm{COO}^{-}$recently has been determined to be $\approx 6$ in uncomplexed enzyme (14). It is increased to $8-9$ in the presence of ligands $(4,14)$, and is probably still higher with good substrates such as $\mathrm{C}_{8} \mathrm{CoA}$ (14-16). Thus, the microscopic $\mathrm{p} K_{\mathrm{a}}$ of the substrate $\alpha \mathrm{C}-\mathrm{H}$ bond should be lowered from an estimated value of $\approx 20$ (17-19) toward $\approx 9$. In the substrate analogue $3 \mathrm{~S}-\mathrm{C}_{8} \mathrm{CoA}$, the use of which was introduced earlier by Thorpe's group (20), we showed that the microscopic $\alpha \mathrm{C}-\mathrm{H} \mathrm{p} K_{\mathrm{a}}$ is lowered from $\approx 16$ in the free state to $\approx 5$ on binding to the active center of hwtMCADH (14). Analogously, with the "chromogenic transition-state analogue" $p$-nitrophenylacetyl-CoA, the same $\mathrm{p} K_{\mathrm{a}}$ is shifted from $\approx 13.6$ to $\approx 5$ (14). It was recognized that the mechanism underlying these large effects is due to tight $\mathrm{H}$-bonds to the ligand thioester carbonyl oxygen. Polarization of specific ligands, due to transfer of charge toward the thioester carbonyl group has been deduced using UV/Vis $(18,21,22)$ and Raman spectroscopy (2325 ). At an early stage of the structure determination (and at a low resolution), it was not clear whether $2^{\prime}-$ or $3^{\prime}-\mathrm{OH}$ of the ribityl group of the FAD was hydrogen bonded to the thioester carbonyl group. To help resolve this point and to assess the importance of the corresponding H-bond, we set out to prepare enzyme reconstituted with both $2^{\prime}$ - and $3^{\prime}$ deoxy-FAD analogues. However, as we refined the structure to a higher resolution $(2.4 \AA)$, it became evident that the carbonyl group of $\mathrm{C}_{8} \mathrm{CoA}$ was hydrogen bonded to $2^{\prime}-\mathrm{OH}$ of the ribityl chain of FAD as well as to the main-chain amide nitrogen atom of Glu376 (26) (distances 2.8 and $3.0 \AA$, respectively).

The primary goal of the present work was the elucidation of the role of these $\mathrm{H}$-bonds in substrate activation, and, if possible, a semiquantitative estimation of the effect. Apo-

\footnotetext{
${ }^{1}$ Abbreviations: ETF, electron-transferring flavoprotein; MCADH, medium-chain acyl-CoA dehydrogenase; pMCADH, pig $\mathrm{MCADH}$; hwtMCADH, recombinant, human wild-type $\mathrm{MCADH} ; \mathrm{C}_{x} \mathrm{CoA}$, straightchain acyl-CoA, where $x$ is the length of the chain; FAD, flavin adenine dinucleotide; 2'-deoxy-FAD-MCADH, pig kidney MCADH reconstituted with 2'-deoxy-FAD; 3'-deoxy-FAD-MCADH, pig kidney MCADH reconstituted with 3'-deoxy-FAD; $3 \mathrm{~S}-\mathrm{C}_{8} \mathrm{CoA}$, 3-thiaoctanoyl-coenzyme A; 4NPA-CoA, 4-nitrophenyl-acetyl-coenzyme A; 4AB-CoA, 4-aminobenzoyl-coenzyme A.
}

Scheme 2: Chemical Structures of Normal FAD, of 2'-Deoxy-FAD, and of 3'-Deoxy-FAD Used in the Present Work $^{a}$

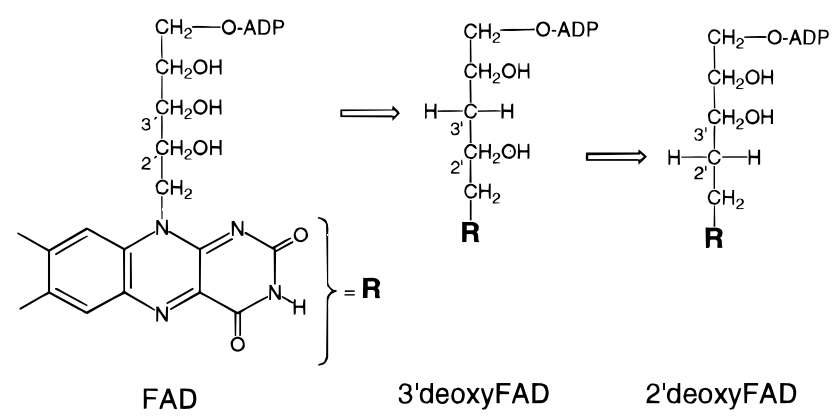

${ }^{a}$ The latter two were used for reconstitution of apo-pMCADH.

pMCADH was reconstituted with $2^{\prime}$-deoxy- and $3^{\prime}$-deoxyFAD (for structures, see Scheme 2). With $2^{\prime}$-deoxy-FAD$\mathrm{MCADH}$, it was expected that substrate and analogue $\alpha \mathrm{C}-\mathrm{H}$ activation and acidity would be reduced drastically due to the absence of the 2'-OH-bond. 3'-Deoxy-FAD-MCADH would serve as a necessary control and, in addition, provide confirmation of the assignment of one of these $\mathrm{H}$-bonds to the ribityl-2'-OH. The extent of $\mathrm{p} K$ shifts induced at the active center of $2^{\prime}$-deoxy-FAD-MCADH was estimated using the transition-state analogues mentioned above. By comparing these results with the $\mathrm{p} K_{\mathrm{a}}$ shift induced in hwtMCADH, we can deduce the specific effect of the ribityl-2'-OH group hydrogen bond. Preliminary reports on this work have been presented $(4,21)$.

\section{MATERIALS AND METHODS}

Instrumentation. UV/Vis spectra, Kontron Uvikon 820 or Uvikon 930 instruments; fluorescence spectra, Perkin-Elmer MFP-44; ${ }^{1} \mathrm{H}$ NMR Spectra, Bruker $250 \mathrm{MHz}$ (WM 250) or JEOL $400 \mathrm{MHz}$ (GX 400). Stopped-flow kinetic measurements, home-built instrument described elsewhere $(27,28)$ which has a dead time of $\approx 3.5 \mathrm{~ms}$ and uses a diode array detector and acquisition software from Spectroscopy Instruments GmbH, Gilching, Germany. The software used for the evaluation of kinetic traces was "program A", a kind gift from Dr. D. Ballou (University of Michigan, Ann Arbor). Graphical work and fitting routines were done with the program KaleidaGraph. Analytical and preparative highperformance liquid chromatography (HPLC) was carried out with a Kontron System equipped with a diode array UV/ Vis detector and a Kontron SFM 25 fluorescence detector. HPLC columns were from Merck $(250 \times 4 \mathrm{~mm}$, Lichrosorb RP-18), preparative cartridges from Waters.

Chemicals. CoASH (sodium salt) was purchased from Pharma-Waldhof (D-40549 Düsseldorf-Oberkassel, Germany), 4-nitrophenylacetone from Lancaster, and 4-aminophenylacetic acid from Fluka. Substrates $\mathrm{C}_{4}$ - to $\mathrm{C}_{16} \mathrm{CoA}$ were either purchased from Sigma or prepared according to refs 29, 30 and purified by preparative HPLC. 4-Nitrophenylacetyl-CoA was obtained as described elsewhere (14). 4-Aminobenzoyl-CoA was synthesized starting from 4-aminophenylacetic acid (Fluka) via its thiophenylester, transesterification with CoASH, and purified by preparative HPLC.

Synthesis. 3'- and 2'-deoxy-FAD were prepared enzymatically from $3^{\prime}$ - and $2^{\prime}$-deoxyriboflavin using partially purified FAD-synthetase essentially as described by Murthy and 
Massey (31) and purified by preparative HPLC. The intermediate $N$-ribityl-o-xylidine was obtained by catalytic $\mathrm{H}_{2}$ reduction of $N$-2'-deoxyribityl-3,4-dimethyl-6-phenylazoaniline (a generous gift from Dr. F. Müller, Novartis, Basel, Switzerland). 3'-Deoxyriboflavin was synthesized starting from 3-deoxyribose (Sigma), which was reacted with 3,4dimethylaniline, hydrogenated, and diazotized according to refs 32, 33. The condensation of diazotized 3'-deoxyribityl3,4-dimethylaniline with barbituric acid according to Tischler et al. (34) yielded the crude product, which was purified by HPLC. Thin-layer chromatography on silica gel in $n-\mathrm{BuOH} /$ acetic acid/ $\mathrm{H}_{2} \mathrm{O}=7 / 2 / 1(\mathrm{v} / \mathrm{v} / \mathrm{v})$. 2'-Deoxyriboflavin and 3'deoxyriboflavin, $R_{f}=0.4$; riboflavin, $R_{f}=0.35$. The structures of 2'-deoxyriboflavin and 2'-deoxy-FAD were confirmed by comparison with samples of the same materials kindly provided by Murthy and Massey (31). pMCADH reconstituted with 2'-deoxy-FAD obtained from Dr. V. Massey is indistinguishable from that described here. The ${ }^{1} \mathrm{H}$ NMR spectrum of 3'-deoxyriboflavin (DMSO, $400 \mathrm{MHz}$ ) is consistent with the assumed structure. The spectrum shows signals of $\mathrm{C}(6)-\mathrm{H}, \mathrm{C}(9)-\mathrm{H}, \mathrm{C}(7)-\mathrm{CH}_{3}$, and $\mathrm{C}(8)-\mathrm{CH}_{3}$ at the same frequencies as those of normal riboflavin under the same conditions and has a multiplet at $\approx 3.0 \mathrm{ppm}$ that is not present in normal riboflavin but can be attributed to $3^{\prime}$ $\mathrm{CH}_{2}-$; this is consistent with the assumed structure.

Reconstitution of apo-pMCADH with FAD Analogues. The apoenzyme was prepared according to ref 35 and had a residual activity $1-2 \%$ that of the holoenzyme. To eliminate any residual activity, the apoenzyme was incubated for 30 min at $4{ }^{\circ} \mathrm{C}$ with 5 equiv (compared with residual holoenzyme) 2-octynoyl-CoA (36). Excess inactivator was subsequently eliminated by ultrafiltration. The apoenzyme obtained in this manner has undetectable levels of activity. Reconstitution was carried out with $\approx 1.2$ equiv of modified $\mathrm{FAD}$ according to ref 35 and was followed by ultrafiltration. The extinction coefficients of both modified MCADHs were estimated to be within $\pm 5 \%$ those of unmodified enzyme, based on the results of comparative titrations with tightly binding ligands such as 3-thiaoctanoyl-CoA, i.e., $\epsilon_{450 \mathrm{~nm}}=$ $15400 \mathrm{M}^{-1} \mathrm{~cm}^{-1}$ (37).

Crystallization, X-ray Data Collection, and Structure Refinement. Reconstituted and purified 2'-deoxy-FADMCADH was dialyzed against buffer containing $10 \mathrm{mM}$ Tris $\mathrm{HCl}, \mathrm{pH} \mathrm{7.5}$, and concentrated to a final concentration of $17.5 \mathrm{mg} / \mathrm{mL}$. Crystallization was carried out by vapor diffusion methods at $4{ }^{\circ} \mathrm{C}$ using the sitting drop technique (38). Diffraction quality crystals were obtained from crystallization drops $(8 \mu \mathrm{L})$, each containing $52.5 \mu \mathrm{g}$ of the enzyme in $50 \mathrm{mM}$ Tris acetate, $50 \mathrm{mM} \mathrm{NaCl}, 4.5 \%$ poly(ethylene glycol) (PEG) 8000, that had been equilibrated against a solution containing 10\% PEG 8000 and $0.1 \mathrm{M} \mathrm{NaCl}$. Crystals of the complex with $\mathrm{C}_{8} \mathrm{CoA}$ were obtained by soaking preformed holoenzyme crystals in mother liquor containing $1.4 \mathrm{mM} \mathrm{C}_{8} \mathrm{CoA}$ for $18 \mathrm{~h}$. No special precautions were taken to keep the crystals in anaerobic conditions.

$\mathrm{X}$-ray data sets were collected at $4{ }^{\circ} \mathrm{C}$, using an R-AXIS IIC image-plate system with $\mathrm{CuK} \alpha$ radiation generated from a Rigaku RU200 rotating anode generator. The resolutions were to $2.1 \AA$ for the holoenzyme crystal and to $2.4 \AA$ for the complex data set. Each data set was obtained from one crystal. The crystal-to-detector distance was $120 \mathrm{~mm}$, the oscillation angle was $1.2^{\circ}$, and the exposure time was 25

\begin{tabular}{|c|c|c|}
\hline & $\begin{array}{l}\text { 2'-deoxy- } \\
\text { FAD- } \\
\text { MCADH }\end{array}$ & $\begin{array}{c}\text { complex of } 2^{\prime}- \\
\text { deoxy-FAD-MCADH } \\
\text { with } \mathrm{C}_{8} \mathrm{CoA}\end{array}$ \\
\hline \multicolumn{3}{|l|}{ data collection } \\
\hline resolution $(\AA)$ & 2.1 & 2.4 \\
\hline number of reflections & 187263 & 139919 \\
\hline number of unique reflections & 46461 & 32693 \\
\hline completeness (\%) & 84.5 & 86.5 \\
\hline$R_{\text {merge }}(\%)^{a}$ & 7.3 & 8.7 \\
\hline \multicolumn{3}{|l|}{$\begin{array}{l}\Lambda_{\text {merge }}(0) \\
\text { refinement }\end{array}$} \\
\hline resolution range used $(\AA)$ & $10-2.1$ & $10-2.4$ \\
\hline number of nonhydrogen atoms & 6068 & 6182 \\
\hline number of water molecules & 264 & 84 \\
\hline$R_{\text {cryst }^{b}}(\%)$ & 18.3 & 19.1 \\
\hline$R_{\text {free }}^{c}(\%)$ & 24.8 & 26.6 \\
\hline$\langle$ overallB $\rangle\left(\AA^{2}\right)$ & 25.0 & 30.7 \\
\hline$\langle$ main-chainB $\rangle\left(\AA^{2}\right)$ & 23.2 & 28.0 \\
\hline$\langle$ side-chainB $\rangle\left(\AA^{2}\right)$ & 26.9 & 32.5 \\
\hline$\langle F A D\rangle\left(\AA^{2}\right)$ & 26.3 & 37.5 \\
\hline$\left\langle\mathrm{C}_{8} \mathrm{CoA}\right\rangle\left(\AA^{2}\right)$ & & $55.5^{d}$ \\
\hline \multicolumn{3}{|l|}{ rms deviation from ideal geometry } \\
\hline bond lengths $(\AA)$ & 0.006 & 0.006 \\
\hline bond angles (deg) & 1.3 & 1.4 \\
\hline
\end{tabular}

${ }^{a} R_{\text {merge }}=\sum_{h} \sum_{i}\left|I_{h i}-\left\langle I_{h}\right\rangle\right| / \sum_{h} \sum_{j} I_{h j}$, where $h$ are unique reflection indices and $i$ indicates symmetry equivalent indices. ${ }^{b} R_{\text {cryst }}=\sum|| F_{\text {obs }} \mid$ $-\left|F_{\text {calc }}\right|\left|/ \sum\right| F_{\text {obs }} \mid$ for all reflections, where $F_{\text {obs }}$ and $F_{\text {calc }}$ are the observed and calculated structure factors, respectively. ${ }^{c} R_{\text {free }}=\sum|| F_{\text {obs }}|-| F_{\text {calc }}|| /$ $\sum\left|F_{\text {obs }}\right|$ for $7 \%$ of the reflections removed at random. ${ }^{d}$ Mean values for the fatty acyl pantetheine moiety of the molecule.

min per frame. Data reduction was performed using the DENZO program package (39). The space group for the holoenzyme crystals is $\mathrm{C} 222_{1}$ and the unit cell dimensions are $a=129.1 \AA, b=136.6 \AA$, and $c=106.0 \AA$. Crystals of the complex are isomorphous to the holoenzyme crystals, and both are isomorphous to the crystals of wild-type pig MCADH (26).

The structure of holo 2'-deoxy-FAD-MCADH and that of the $\mathrm{C}_{8} \mathrm{CoA}$ complex were solved by the difference Fourier method using the structure of pig liver MCADH (PDB code, 1MDD) and that of the MCADH $-\mathrm{C}_{8} \mathrm{CoA}$ complex (PDB code, $1 \mathrm{MDE}$ ). Refinements were carried out using X-PLOR (40) and TURBO-FRODO graphic software (41). Data collection statistics and the refinement results are summarized in Table 1. A difference Fourier map confirmed that the FAD in the enzyme is indeed 2'-deoxy-FAD (see Figure 6, below).

Miscellaneous. Anaerobic solutions were obtained by applying at least five cycles of evacuation/flushing with oxygen-free argon, in the presence of glucose/glucose oxidase/catalase (Boehringer) or protocatechuate dioxygenase (a gift from Dr. D. Ballou, University of Michigan)/ protocatechuate in quantities sufficient to eliminate residual $\left[\mathrm{O}_{2}\right]$ in the micromolar range. Typically, such samples were incubated in an anaerobic cuvette at $4-8^{\circ} \mathrm{C}$ for ca. $12-16$ $\mathrm{h}$ before the substrate was added from the side arm of the cuvette to the enzyme solution. This procedure was necessary to obtain reliable rate constants for the reaction of 2'-deoxyMCAD and $\mathrm{C}_{8} \mathrm{CoA}$. Unless otherwise stated, all optical spectra were recorded at $25{ }^{\circ} \mathrm{C}$ using $50 \mathrm{mM}$ potassium phosphate, $\mathrm{pH}$ 7.5. Activity assays were carried out under the same conditions using the ferricenium assay (42).

\section{RESULTS}

3'-Deoxy-FAD-pMCADH. The UV/Vis absorption spectrum of 3'-deoxy-FAD-pMCADH (Table 2) is essentially 
Table 2: Comparison of Spectral Properties of Native, of 3'-deoxy-FAD- and of 2'-deoxy-FAD-MCADH Complexed with Various Acyl-CoA Ligands

\begin{tabular}{|c|c|c|c|c|c|c|}
\hline \multirow[b]{2}{*}{ ligand } & \multicolumn{2}{|c|}{ native pMCADH } & \multicolumn{2}{|c|}{ 3'-deoxy-FAD-MCADH } & \multicolumn{2}{|c|}{ 2'-deoxy-FAD-MCADH } \\
\hline & $\lambda_{\max }(\mathrm{nm})$ & $\epsilon\left(\mathrm{mM}^{-1} \mathrm{~cm}^{-1}\right)$ & $\lambda_{\max }(\mathrm{nm})$ & $\epsilon\left(\mathrm{mM}^{-1} \mathrm{~cm}^{-1}\right)$ & $\lambda_{\max }(\mathrm{nm})$ & $\epsilon\left(\mathrm{mM}^{-1} \mathrm{~cm}^{-1}\right)$ \\
\hline no ligand & $448 / 372$ & $15.4(448)$ & $448 / 372$ & $15.4(448)^{a}$ & $441 / 372$ & $15.4(441)^{a}$ \\
\hline $\mathrm{C}_{8} \mathrm{CoA}$ & 572 & $\approx 2.5^{b}$ & 572 & $1.9^{c}$ & $d$ & $d$ \\
\hline 3-ketooctanoyl-CoA & $560 / 300^{e}$ & $\approx 3.5 / \approx 8.6^{e f f}$ & nd & nd & -1306 & $\approx 1.5^{g} / 9.5^{f}$ \\
\hline 4NPA-CoA $f^{f}$ & $740 / 489$ & $2.9 / 9.0$ & $740 / 499$ & $3.1 / 7.9$ & $d$ & $d$ \\
\hline $3 \mathrm{~S}-\mathrm{C}_{8} \mathrm{CoA}$ & $804^{h}$ & $8.7^{h}$ & nd & nd & $d$ & $d$ \\
\hline octyl-CoA ${ }^{f}$ & 493 & $\approx 4$ & nd & nd & 488 & $\approx 2.2$ \\
\hline $4 \mathrm{AB}-\mathrm{CoA}^{f}$ & 366 & 22.2 & 366 & 25.0 & 354 & 19.2 \\
\hline
\end{tabular}

${ }^{a}$ Estimated to be within $\pm 5 \%$ that of pMCADH (see Materials and Methods). ${ }^{b}$ Estimated from ref $37 .{ }^{c}$ Estimated with a 2.1-fold excess of substrate. ${ }^{d}$ No long wavelength absorption observed. ${ }^{e}$ Estimated from Figure 1 in ref $53 .{ }^{f}$ Estimated from the difference spectra between fully complexed and uncomplexed enzyme. ${ }^{g}$ At $\lambda=560 \mathrm{~nm}$ (long-wavelength absorption has no maximum). ${ }^{h}$ From ref 20 . nd: not determined.

Table 3: Comparison of Selected Parameters of 3'-deoxy-FAD- and 2'-deoxy-FAD-MCADH with Those of pMCADH $^{a}$

\begin{tabular}{|c|c|c|c|c|c|c|}
\hline ligand & parameter & $\begin{array}{c}\text { native } \\
\text { pMCADH }\end{array}$ & $\begin{array}{l}\text { 3'-deoxy- } \\
\text { FAD-MCADH }\end{array}$ & $\begin{array}{l}\text { 2'-deoxy- } \\
\text { FAD-MCADH }\end{array}$ & $\begin{array}{c}\text { pMCADH/ } \\
\text { 2'-deoxy-FAD-MCADH }^{\prime}\end{array}$ & $\begin{array}{c}\Delta \Delta G_{\text {app }} \\
\left(\mathrm{kJ} \mathrm{mol}^{-1}\right)^{b}\end{array}$ \\
\hline \multirow[t]{2}{*}{$\mathrm{C}_{8} \mathrm{CoA}$} & turnover $^{c}$ & $100 \pm 5 \%$ & $100 \pm 5 \%$ & $<0.1$ & & \\
\hline & $k_{2}\left(\mathrm{~s}^{-1}\right)$ & $320^{d}$ & & $2.1 \times 10^{-5 e}$ & $\approx 1.5 \times 10^{7}$ & $\approx 38$ \\
\hline 3-ketooctanoyl-CoA & $K_{\mathrm{d}}(\mu \mathrm{M})$ & $0.055^{f}$ & & 3.2 & $\approx 0.017$ & $\approx 9$ \\
\hline \multirow[t]{2}{*}{ 4NPA-CoA } & $K_{\mathrm{d}}(\mu \mathrm{M})$ & $93^{g}$ & $100^{g}$ & $\approx 60$ & $\approx 1$ & \\
\hline & $\mathrm{p} K_{\mathrm{a}}(\alpha \mathrm{C}-\mathrm{H})$ & $\approx 5^{h}$ & nd & $>10$ & & $>30$ \\
\hline \multirow[t]{2}{*}{$3 \mathrm{~S}-\mathrm{C}_{8} \mathrm{CoA}$} & $K_{\mathrm{d}}(\mu \mathrm{M})$ & $0.47^{g, i}$ & nd & 3.0 & & \\
\hline & $\mathrm{p} K_{\mathrm{a}}(\alpha \mathrm{C}-\mathrm{H})$ & $\approx 5^{h}$ & nd & $\approx 11$ & & $\approx 35$ \\
\hline octyl-CoA & $K_{\mathrm{d}}(\mu \mathrm{M})$ & $4.0^{f}$ & nd & 21 & $\approx 0.2$ & $\approx 1.0$ \\
\hline $4 \mathrm{AB}-\mathrm{CoA}$ & $K_{\mathrm{d}}(\mu \mathrm{M})$ & 12.8 & 17 & 6 & $\approx 2$ & $\approx-0.4$ \\
\hline
\end{tabular}

${ }^{a}$ All parameters were determined in $50 \mathrm{mM} \mathrm{KP}$ buffer, $\mathrm{pH} 7.8$ and at $25{ }^{\circ} \mathrm{C}$, if not indicated otherwise. ${ }^{b}$ Differences in Gibbs activation energies $\Delta \Delta G_{\text {app }}$ were estimated from the ratios pMCADH/2'-deoxy-FAD-MCADH. ${ }^{c}$ Refs $9,42 .{ }^{d}$ Ref $52, d$ etermined at $5{ }^{\circ} \mathrm{C} .{ }^{e}$ Determined at 1 ${ }^{\circ} \mathrm{C} .{ }^{f}$ Ref $53 .{ }^{g} K_{d, \text { app }}$, this value includes the equilibrium constant for deprotonation, cf. (ref 14) for details. ${ }^{h}$ Estimated for hwtMCADH (14). ${ }^{i}$ Ref 20.

identical with that of native pMCADH (37). To assess the intrinsic activity of $3^{\prime}$-deoxy-FAD-MCADH, the $<2 \%$ residual activity present in apo-MCADH was eliminated by inactivation with 2-octynoyl-CoA (36); this leads to protein with undetectable MCADH activity in the ferricenium assay (42). At saturating substrate concentrations, $3^{\prime}$-deoxy-FADMCADH has the same catalytic activity as pMCADH (Table 3). The spectral changes observed upon reaction of oxidized 3 -deoxy-FAD-MCADH with $\mathrm{C}_{8} \mathrm{CoA}$, and the corresponding extent of reduction (Table 2), are essentially the same as those described by Thorpe et al. (37) for normal pMCADH. Also, the effects observed on binding of substrate analogues (Table 2) are closely similar to those of the parent pMCADH.

2'-Deoxy-FAD-pMCADH, Preparation, Some Properties, and Reaction with $\mathrm{C}_{8} \mathrm{CoA}$. The optical properties of oxidized 2'-deoxy-FAD-MCADH (Figure 1, Table 2) are similar but not identical with those of the parent MCADH (37). Specifically, in the $2^{\prime}$-deoxy-FAD enzyme the main band in the visible range is more resolved and blue-shifted by $\approx 8$ $\mathrm{nm}$ to $\approx 440 \mathrm{~nm}$ at $\mathrm{pH} 7.8$. The $2 \mathrm{e}^{-}$redox potential was determined potentiometrically to be $-165 \mathrm{mV}$ at $\mathrm{pH} 7.6$, based on the methods described in (43), and is thus 30-40 $\mathrm{mV}$ lower than that of pMCADH (44). This should be compared with the $2 \mathrm{e}^{-}$redox potential of free $2^{\prime}$-deoxy-FAD (31), which is also somewhat lower $(\approx-220 \mathrm{mV})$ than that of free FAD $(\approx-207 \mathrm{mV})(45)$.

Using the ferricenium assay (42) at a concentration of $\mathrm{C}_{8^{-}}$ CoA sufficient to achieve saturation $(50 \mu \mathrm{M}$, i.e., $\approx 15 \times$ $K_{\mathrm{m}}$ of pMCADH), no catalytic activity of 2'-deoxy-FADMCADH could be detected. However, $\mathrm{C}_{8} \mathrm{CoA}$ undergoes a chemical transformation upon binding to $2^{\prime}$-deoxy-FADMCADH as shown by the experiment depicted in Figure 1A.
Aerobic or anaerobic addition of $\mathrm{C}_{8} \mathrm{CoA}$ to the enzyme induces a marked perturbation of the oxidized flavin spectrum. This is typical for the formation of CoA complexes with either slowly reacting substrates $(11,46)$ or with substrate analogues such as $n$-alkyl-CoA thioethers (47), which do not undergo chemical conversion. The use of 2'deoxy-FAD-MCADH appears to be a simple method for assessing spectral effects induced by ligand binding. The difference spectrum between 2'-deoxy-FAD-MCADH (unliganded) and 2'-deoxy-FAD-MCADH complexed with $\mathrm{C}_{8^{-}}$ CoA (Figure 1B) is essentially identical with that obtained on binding $\mathrm{C}_{8} \mathrm{CoA}$ to Glu376Gln-hMCADH (9). This active site mutant has a very low level of flavin reduction activity due to the absence of the $\alpha$-proton abstracting base Glu376$\mathrm{COO}^{-}$. We interpret the close similarity of these difference spectra as strong evidence for identical modes of substrate binding in both 2'-deoxy-FAD- and native MCADH.

The spectrum of trace 1 in Figure 1A remains essentially unaltered in the presence of oxygen. However, under strictly anaerobic conditions, a very slow decrease of the visible absorbance ensues (see also Figure 1A, inset). This leads monophasically, with a $t_{1 / 2} \approx 3.8 \mathrm{~h}\left(k_{\mathrm{obs}} \approx 5.1 \times 10^{-5} \mathrm{~s}^{-1}\right)$, to the final species represented by curve 4 , Figure $1 \mathrm{~A}$. This species is a mixture of approximately 60/40 oxidized/reduced 2'-deoxy-FAD-MCADH (complexed to either substrate or product). Admission of oxygen leads to rapid (re)formation of oxidized enzyme corresponding to curve 1 . The fact that complete reduction is not attained, i.e., the extent of flavin reduction is $\approx 40 \%$ of that observed with pMCADH, probably is not caused by the presence of residual oxygen, by heterogeneity of the preparation, or by modified kinetic behavior. This extent of reduction was observed reproducibly 

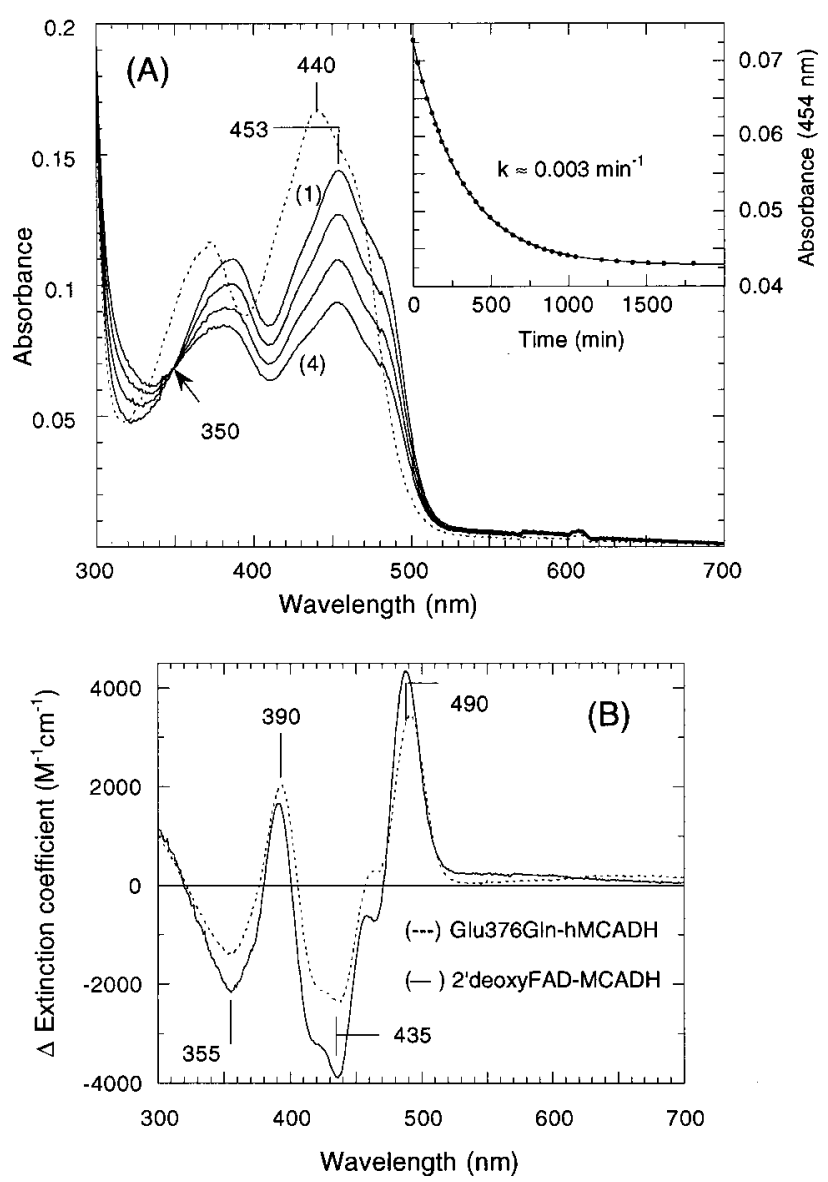

FIGURE 1: Binding of the substrate octanoyl-CoA to 2'-deoxy-FAD$\mathrm{MCADH}$, and the spectral course of the reaction. (A) An anaerobic solution of the enzyme, $10.5 \mu \mathrm{M}$ in $50 \mathrm{mM} \mathrm{KP}_{\mathrm{i}}, \mathrm{pH} 7.8$ (curve - - ) was reacted at $\approx 1{ }^{\circ} \mathrm{C}$ with $500 \mu \mathrm{M} \mathrm{C} \mathrm{C}_{8} \mathrm{CoA}$, and the ensuing spectral changes were recorded. Curves 1,2 , and 3 were taken after $30 \mathrm{~s}, 100 \mathrm{~min}$, and $275 \mathrm{~min}$, respectively. Curve 4 was recorded at the end of the reaction $(t=24 \mathrm{~h})$. Curves $1-4$ are corrected for dilution. The arrow denotes an isosbestic point between substratecomplexed, oxidized MCADH, and its reduced form. The insert depicts the time dependence of absorption decrease at $454 \mathrm{~nm}$ measured in a companion experiment under anaerobic conditions using $5.5 \mu \mathrm{M} 2^{\prime}$-deoxy-FAD-MCADH and $500 \mu \mathrm{M} \mathrm{C} \mathrm{C}_{8} \mathrm{CoA}$ in 50 $\mathrm{mM} \mathrm{KP}, \mathrm{pH} 7.8$ and at $0-1{ }^{\circ} \mathrm{C}$. The full line through the data points is the best fit for a monophasic relaxation process. (B) Difference spectra between uncomplexed (curve - - , panel A) and $\mathrm{C}_{8} \mathrm{CoA}$-complexed 2'-deoxy-FAD-MCADH (curve (1), panel A) are derived from the curves of Figure 1A. The corresponding difference spectrum obtained with Glu376GlnMCADH (curve - - -, Figure 1B) (Kieweg, V., and Ghisla, S., unpublished) is shown for comparison.

in several experiments, whereas the usual extent of reduction was found with MCADH reconstituted with normal FAD (37). As a comparison, we also used Glu376Gln-MCADH, a mutant that exhibits a very slow rate of substrate reduction (9) similar to that of 2'-deoxy-FAD-MCADH. With this mutant, the extent of reduction is $80-90 \%$ of the maximally attainable value, i.e., similar to that of normal pMCADH (37). From these results it appears that the different extent of flavin reduction in $2^{\prime}$-deoxy-FAD-MCADH is induced by the different properties of $2^{\prime}$-deoxy-FAD itself.

This behavior can be explained by comparison with the variable extent of reduction of oxidized MCADH observed with various substrates $(37,48)$ and of MCADH reconstituted with FAD analogues with different redox potentials (49). As discussed elsewhere $(11,37,46)$ the reaction of MCADH
Scheme 3: Kinetic Scheme for the Reductive "Half-Reaction" of MCADH with Substrate ${ }^{a}$

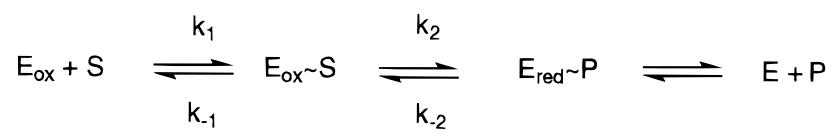

${ }^{a} E_{\mathrm{ox}}=$ oxidized; $E_{\text {red }}=$ reduced $\mathrm{MCADH} ; \mathrm{S}=$ substrate; $\mathrm{P}=$ product. $k_{1}$ and $k_{-1}$ represent substrate binding/dissociation, $k_{2}$ and $k_{-2}$ $=$ substrate dehydrogenation and hydrogenation, respectively.

with substrates approaches to the equilibrium of $E_{\mathrm{ox}} \sim \mathrm{S}$ and $E_{\text {red }} \sim \mathrm{P}$ as represented in Scheme 3, where the overall equilibrium between oxidized and reduced MCADH species reflects the ratio of $k_{2} / k_{-2}$, i.e., the internal redox equilibrium and the equilibria of $\mathrm{S}$ and $\mathrm{P}$ binding to $E_{\mathrm{ox}}$ and $E_{\text {red }}$. With pMCADH $k_{2} / k_{-2} \approx 9 / 1$ (50), the effect observed with 2 -deoxy-FAD-MCADH is thus reasonably attributed to the rates of (de)hydrogenation, steps $k_{2}$ and $k_{-2}$ being approximately equivalent. The smaller ratio $k_{2} / k_{-2}$ in the 2 deoxy-FAD enzyme is in accordance with its $30-40 \mathrm{mV}$ lower redox potential compared with pMCADH.

From the relationship $k_{\text {obs }}=k_{2}+k_{-2}(51)$, a value of $\approx 2.1$ $\times 10^{-5} \mathrm{~s}^{-1}$ for $k_{2}$ can be estimated.

For the reduction of native pMCADH with $\mathrm{C}_{8} \mathrm{CoA}$, a value of $k_{2}=320 \mathrm{~s}^{-1}$ at $5{ }^{\circ} \mathrm{C}$ was reported by Kumar and Srivastava (52). The removal of the FAD-2'-OH group that results in the elimination of the corresponding $\mathrm{H}$-bond to the substrate thioester carbonyl, thus causes a $\approx 1.5 \times 10^{7}$ fold decrease in the rate of substrate dehydrogenation. It is noteworthy that no charge-transfer band is observed at $\lambda>$ $500 \mathrm{~nm}$ upon reduction, whereas this is a prominent feature of the reduced MCADH-product complex (37). This could be due to either a preferential displacement of the reduced enzyme $\sim$ enoyl-CoA complex by excess substrate or, more likely, the absence of the charge-transfer effect itself in the $E_{\text {red }} \sim \mathrm{P}$ complex. The absence of the CT absorbance would be in keeping with the concept that hydrogen bonds to the thioester carbonyl are important for the manifestation of the charge-transfer interaction, as suggested by resonance Raman spectroscopy (23).

$2^{\prime}$-Deoxy-FAD-MCADH and $3 S-C_{8} C o A$. This analogue (structure, see Scheme 4, A) was first introduced by Lau et al. (20) for the study of the interactions with oxidized acylCoA dehydrogenases. It has an estimated $\mathrm{p} K$ for deprotonation at position $\alpha \mathrm{C}-\mathrm{H}$ of $\approx 16$. Upon binding to MCADH it forms a deeply colored complex with a $\lambda_{\max }$ in the 800 to $820 \mathrm{~nm}$ region, due to a charge-transfer transition (20) (Figure 2). This absorption is caused by the interaction of the enzyme-oxidized flavin (acceptor) and the analogue anionic form (donor) that results from deprotonation of the ligand $\alpha \mathrm{C}-\mathrm{H}[\mathrm{p} K \approx 5.2$ when bound to MCADH (14)]. In addition, the oxidized flavin visible band is perturbed and blue-shifted by $\approx 8 \mathrm{~nm}$. $3 \mathrm{~S}-\mathrm{C}_{8} \mathrm{CoA}$ also binds tightly to $2^{\prime}$ deoxy-FAD-MCADH (Table 3), however, in the $\mathrm{pH}$ range 6 to $\approx 9$, the spectral effects are strikingly different from those found with hwtMCADH. The visible band of the oxidized flavin is more resolved and red-shifted, and no long wavelength absorbance is found. These characteristics indicate that ligand deprotonation at the $\alpha$-position has not occurred (Figure 2) $(14,20)$. More importantly, however, at the higher $\mathrm{pH}$ of 10 , addition of excess $3 \mathrm{~S}-\mathrm{C}_{8} \mathrm{CoA}$ leads to formation of a faint and broad absorbance band in the 800 $\mathrm{nm}$ region, which at its maximum has $\approx 8 \%$ the intensity of 
Scheme 4: Proposed Mode of Interaction of $3 \mathrm{~S}-\mathrm{C}_{8} \mathrm{CoA}(\mathrm{A})$, 4NPA-CoA (B), and 4AB-CoA (C) with the Active-Site Functional Groups of MCADH, and Comparison with the Interaction of the Substrate-Derived Transition State ${ }^{a}$

(A)

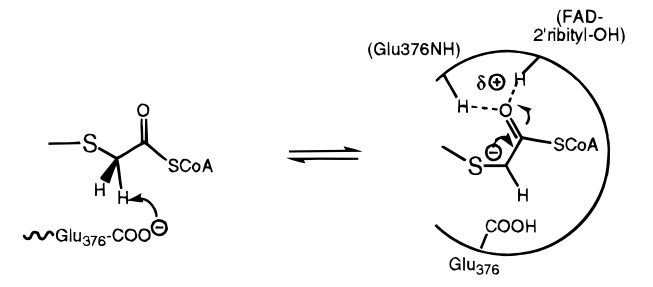

(B)

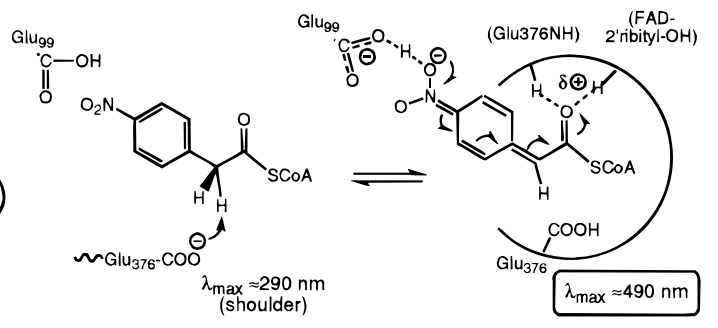

(C)
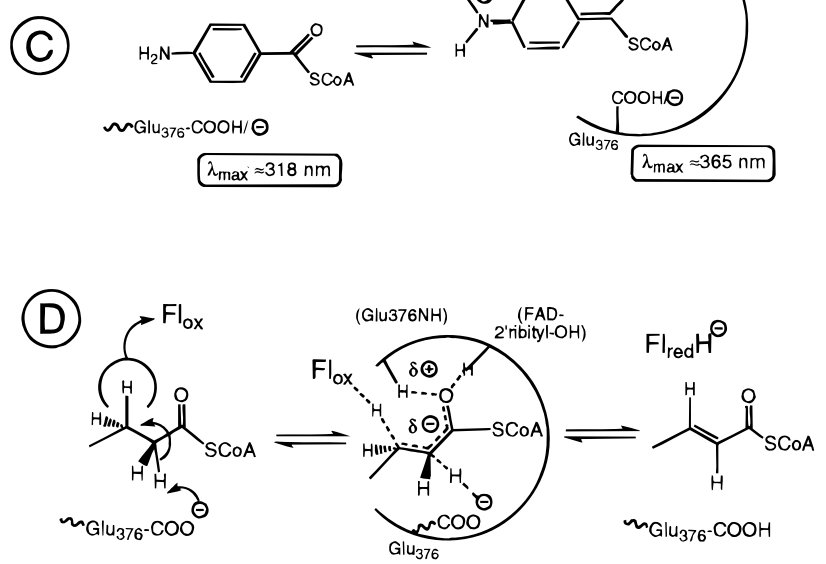

${ }^{a}$ The induced polarization of the respective chromophores and the resulting absorbances are also shown. The protonation state in (C) is uncertain. The hydrogen bond(s) of the thioester carbonyl shown are toward the FAD-ribityl-2'-OH and the Glu376-backbone-NH. Note that the deprotonated acyl-CoA analogues in (A) and (B) can be regarded as transition-state analogues because they mimic the partially negatively charged species resulting during $\mathrm{H}^{+}$abstraction from substrate $\alpha \mathrm{C}-\mathrm{H}$. During catalysis rupture of the $\alpha \mathrm{C}-\mathrm{H}$ bond is initiated before that of the $\beta \mathrm{C}-\mathrm{H}$ in a concerted mechanism (11).

the corresponding band obtained with MCADH (Figure 2). At this $\mathrm{pH}$, a titration cannot be carried out because of the instability of the system. It is clear, however, that this absorption reflects partial ionization of the ligand $\alpha \mathrm{C}-\mathrm{H}$. From the extent of charge-transfer absorption, a $\mathrm{p} K_{\mathrm{a}}$ of 11 is estimated, based on the assumption that at $\mathrm{pH} \gg \mathrm{pK}$ the extinction of the CT-complex in 2'-deoxy-FAD-MCADH is the same as that with hwtMCADH, i.e., $8600 \mathrm{M}^{-1} \mathrm{~cm}^{-1}(14$, 20).

2'-Deoxy-FAD-MCADH and 4-Nitrophenylacetyl-CoA (4NPA-COA). The properties of this analogue (structure, see Scheme 4, B) and of similar ones derived from phenylacetyl$\mathrm{CoA}$, as well as their interactions with hwtMCADH and its mutants, have been reported in detail elsewhere (14). In the

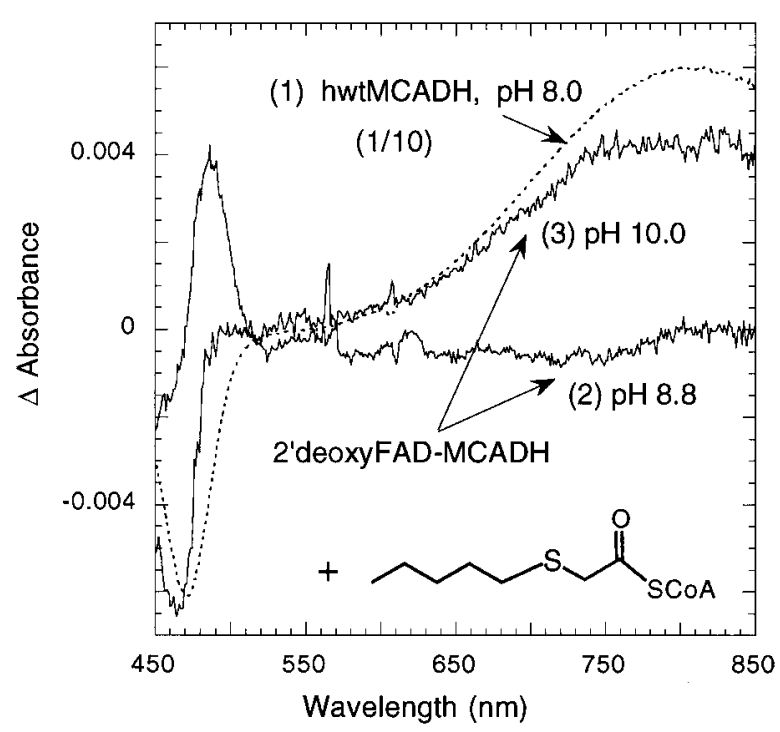

FIGURE 2: Interaction of 2'-deoxy-FAD-MCADH with $3 S_{-}-C_{8} C o A$ and comparison with hwtMCADH. The absorbance spectrum of hwtMCADH, $11 \mu \mathrm{M}$ in $50 \mathrm{mM}$ Tris/HCl buffer, $\mathrm{pH}$ 8.0, containing $250 \mathrm{mM} \mathrm{KCl} \mathrm{(14)} \mathrm{was} \mathrm{recorded} \mathrm{in} \mathrm{the} \mathrm{presence} \mathrm{and} \mathrm{absence} \mathrm{of} 5$ equiv $3 \mathrm{~S}-\mathrm{C}_{8} \mathrm{CoA}$. Curve 1 is the difference spectrum between the two. Curves 2 and 3 correspond to the difference spectra obtained in similar experiments using 2'-deoxy-FAD-MCADH at $\mathrm{pH} 8.8$ (Tris buffer) and pH 10.0 (50 mM glycine/KOH buffer), respectively. Note that the spectrum of the complex with hwtMCADH has been reduced by $1 / 10$ for comparison. At $\mathrm{pH} 10$ a full titration could not be carried out because of instability of the enzyme.

present context it is important to reiterate that upon binding, 4NPA-CoA $\left(\alpha \mathrm{C}-\mathrm{H} \mathrm{p} K_{\mathrm{a}}\right.$ of free analogue $\left.\approx 13.6\right)$ deprotonates with an apparent $\mathrm{p} K=5$. The anionic form has a characteristic absorption maximal around $490 \mathrm{~nm}$ and induces a charge-transfer absorption with a maximum around 750 $\mathrm{nm}$. This is demonstrated for pMCADH in Figure 3A. In marked contrast, binding of 4NPA-CoA to $2^{\prime}$-deoxy-FADMCADH induces only minor perturbations of the spectrum of the oxidized flavin (Figure 2A). Although these changes indicate tight binding (Table 3), the absence of the specific absorbance band at $\approx 490 \mathrm{~nm}$ clearly demonstrates that $\alpha$-deprotonation does not occur. Increasing the $\mathrm{pH}$ to 9 results in no spectral effects indicative of 4NPA-CoA anion formation. With 3'-deoxy-FAD-MCADH, the same complex is observed as with native MCADH (not shown, Table 2). Attempts to obtain crystals of 2'-deoxy-FAD-MCADH complexed with 4NPA-CoA by either soaking or cocrystallization have not been successful. Several data sets were collected but no ligand was found in the structure (data not shown), suggesting that the complex of $2^{\prime}$-deoxy-FADMCADH with 4NPA-CoA is apparently not stable under the crystallization conditions.

2'-Deoxy-FAD-MCADH and 3-Ketooctanoyl-CoA. 3-Ketooctanoyl-CoA has a much lower $\alpha \mathrm{C}-\mathrm{H} \mathrm{p} K_{\mathrm{a}}(\approx 8.7-9.0$ for free ligand) than other $\mathrm{CoA}$ substrates and analogues. It binds in its anionic form to native pMCADH and forms a typical charge-transfer complex (53). In this context it can be regarded as a transition-state analogue. With 2'-deoxyFAD-MCADH, a comparable spectral behavior is observed and ligand anion formation is indicated by the appearance of a characteristic band at $306 \mathrm{~nm}$ (Figure 4). However, the charge-transfer absorption band is of much lower intensity and strongly shifted to the blue compared with that observed with MCADH (53). This shift is in accord with the more 

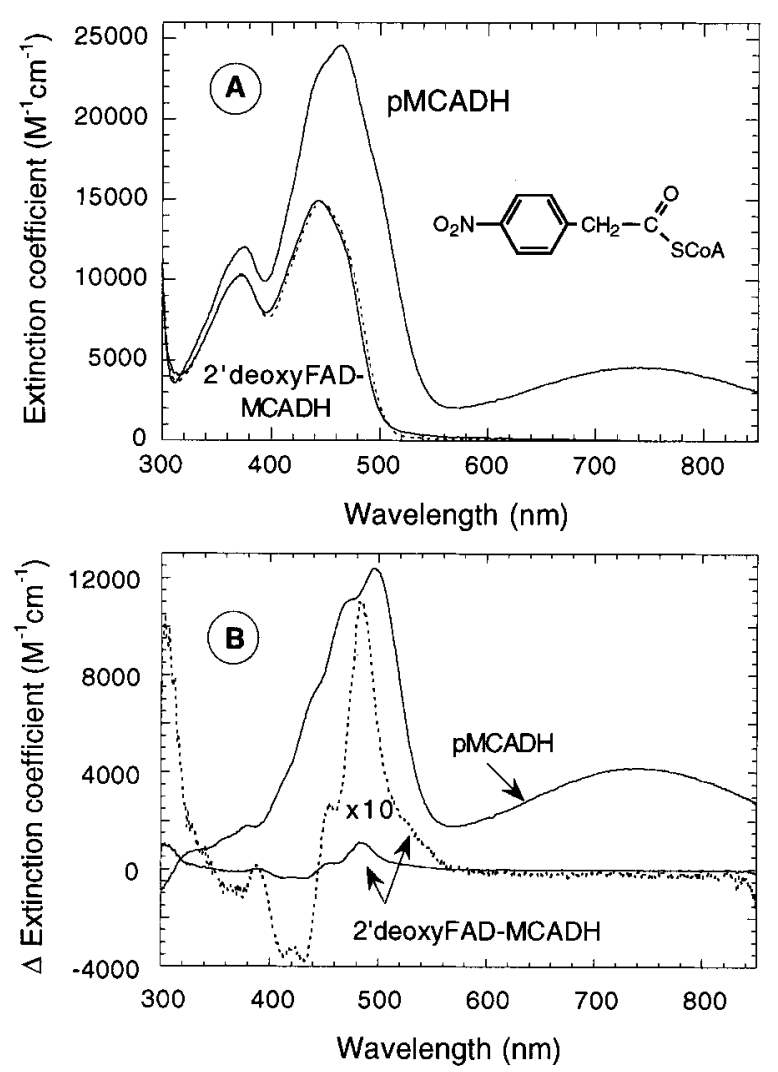

FIGURE 3: Effect of 4NPA-CoA on the absorption spectrum of 2'deoxy-FAD-MCADH and comparison with pMCADH. (A) 2'deoxy-FAD-MCADH, $17.3 \mu \mathrm{M}$ in $50 \mathrm{mM} \mathrm{KP}$, pH 7.8 and $25^{\circ} \mathrm{C}$ $(-)$. To this sample and to the reference cuvette 22 equiv of 4NPACoA were added. The spectrum of the complex (- - -) is corrected for dilution. The spectrum of the complex of unmodified $\mathrm{pMCADH}$ with 4NPA-CoA is shown for comparison (-). (B) Difference spectra between uncomplexed and complexed species. Note, the curve (- -) is a 10-fold magnification of the 2'-deoxy-FADMCADH difference spectrum.

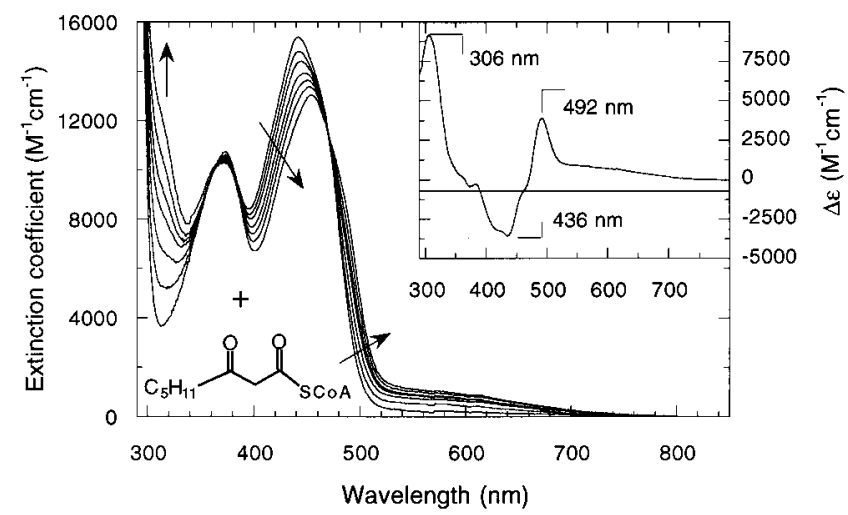

FIGURE 4: Spectral effects induced upon binding of 3-ketooctanoylCoA to 2'-deoxy-FAD-MCADH. The spectra of the enzyme, 10.6 $\mu \mathrm{M}$ in $50 \mathrm{mM} \mathrm{KP}, \mathrm{pH} 7.8$ and at $25^{\circ} \mathrm{C}$ in the presence of $0,0.25$, $0.5,0.79,1.08,1.8$, and 10.8 equiv are shown. The same amounts of ligand were added to the reference cuvette. The inset shows the difference spectrum between complexed and free enzyme.

negative redox potential of $2^{\prime}$-deoxy-FAD-MCADH. Binding of anionic 3-ketooctanoyl-CoA to 2'-deoxy-FAD-MCADH is $\approx 60$-fold weaker than binding to the parent MCADH (Table 3). This finding supports the concept that the 2'-OH hydrogen bond to the thioester contributes to the stabilization of the anionic transition state.

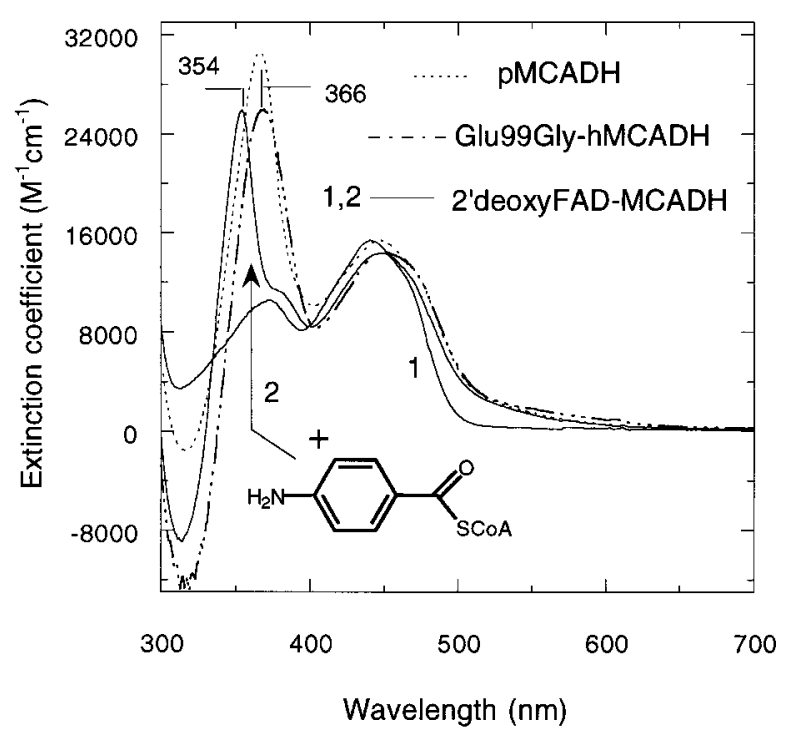

FIGURE 5: Interaction of MCADH and 2'-deoxy-FAD-MCADH with the chromogenic ligand $4 \mathrm{AB}-\mathrm{CoA}$. (curve 1, -): spectrum of 2'-deoxy-FAD-MCADH, $10.8 \mu \mathrm{M}$, in $50 \mathrm{mM} \mathrm{KP}_{\mathrm{i}}$ at $\mathrm{pH} 7.8$ and $25^{\circ} \mathrm{C}$. (curve 2, - ): same sample in the presence of 8 equiv $4 \mathrm{AB}-\mathrm{CoA}$. The negative absorbance with a $\lambda_{\max }=315 \mathrm{~nm}$ is that of free $4 \mathrm{AB}-\mathrm{CoA}\left(\lambda_{\max }=318 \mathrm{~nm}\right)$ present in the reference cuvette at the same concentration. $\cdots, \mathrm{pMCADH}$ (same concentration and conditions) in the presence of 5 equiv $4 \mathrm{AB}-\mathrm{CoA}$; - - - ; analogous experiment with Glu99Gly hMCADH. The spectra are corrected for dilution.

2'-Deoxy-FAD-MCADH and 4-Aminobenzoyl-CoA (4AB$C O A)$. The chromophore of this substrate analogue consists of a highly delocalizable $\pi$-electron system in which the 4-amino group has donor properties and the thioester group has acceptor properties, as shown in Scheme 4 (C). Clearly, interactions with the thioester carbonyl as a consequence of binding are expected to significantly affect the polarization of the $\pi$-system and thus the UV/Vis spectrum of the analogue.

In this respect $4 \mathrm{AB}-\mathrm{CoA}$ is anticipated to behave similarly to the polarizable product analogues recently described by Thorpe's group (16). Binding of $4 \mathrm{AB}-\mathrm{CoA}$ to pMCADH is relatively tight (Table 3 ) and accompanied by marked spectral effects. The band of the free chromophore (Figure $5, \lambda_{\max }=315 \mathrm{~nm}$ ) disappears and is replaced by a band with a $\lambda_{\max }=366 \mathrm{~nm}$ (Figure 5) and a weak, long-wavelength band extending beyond $600 \mathrm{~nm}$. The latter absorption is attributed to a charge-transfer interaction between the 4-aminobenzoyl moiety as donor and the oxidized flavin as acceptor. We attribute the new band with a $\lambda_{\max }=366 \mathrm{~nm}$ to the formation of a new, strongly polarized chromophore as shown in Scheme 4, C, in which electronic charge is displaced extensively toward the thioester moiety. The observed effect is unlikely to originate in simple polarity changes in the microenvironment of the chromophore: The $\lambda_{\max }$ of the $\pi-\pi^{*}$ transition of 4-aminobenzoyl-thiophenylester, which was synthesized as a model compound, undergoes a blue-shift on going from polar to nonpolar solvents, i.e., opposite to what is observed in the enzyme complex $\left(\mathrm{MeOH}, \lambda_{\max }=324 \mathrm{~nm} ; \mathrm{CH}_{2} \mathrm{Cl}_{2}, \lambda_{\max }=312 \mathrm{~nm}\right.$; hexane, $\lambda_{\max }=299 \mathrm{~nm}$, not shown). The effect also is not caused by an interaction with Glu99-COOH. This residue flanks the bottom of the MCADH active center and has been shown to interact with 4NPA-CoA (14). Addition of 4AB-CoA to the 


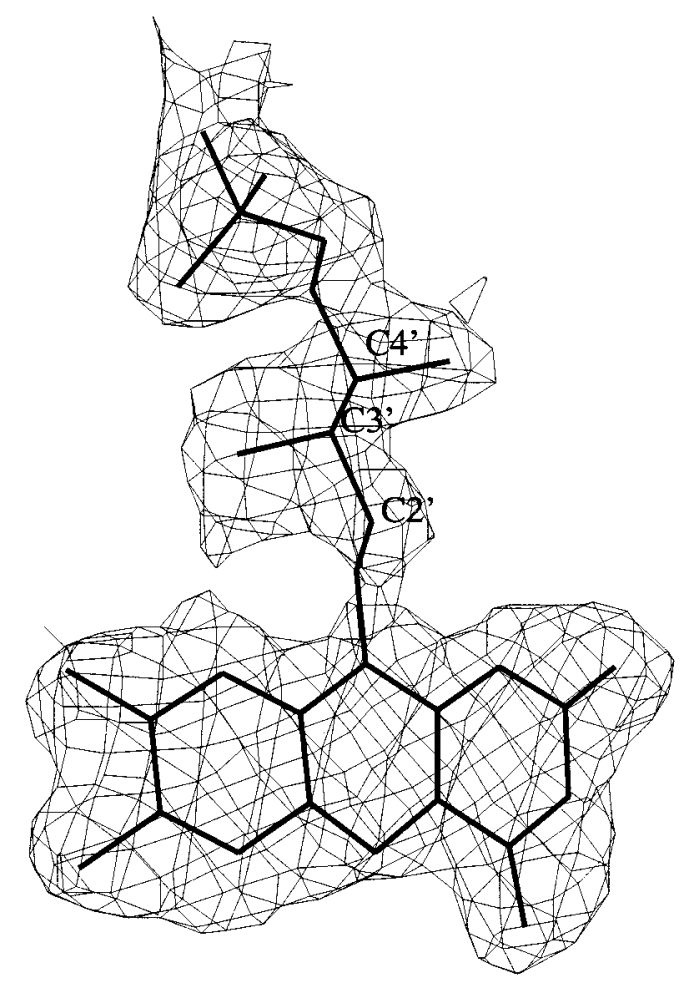

FIGURE 6: A $2 F_{\mathrm{o}}-F_{\mathrm{c}}$ difference Fourier map of the $2^{\prime}$-deoxy-FADMCADH structure fitted with a model of $2^{\prime}$-deoxy-FAD. The density at the 2 -position clearly lacks the hydroxyl group compared with the densities at $3^{\prime}$ - and $4^{\prime}$-positions. The electron density was contoured at the 1.0 -s level.

Glu99Gly mutant of hMCADH results in a complex that has the band of the polarized transition at exactly the same wavelength as with unmodified MCADH (Figure 5). Some minor spectral differences mainly affecting the visible flavin band (Figure 5) can be attributed to the differences between pig and human MCADH. The $K_{\mathrm{d}}$ for binding to this mutant $(\approx 14 \mu \mathrm{M})$ is essentially identical with that for pMCADH (Table 3), and this is compatible with the same mode of binding.

Binding of 4AB-CoA to 3'-deoxy-FAD-MCADH induces the same effects as binding to unmodified pMCADH (Table 2 ). With 2 '-deoxy-FAD-MCADH the observed effects are markedly different (Figure 5, Table 2). Thus $\lambda_{\max }$ of the bound 4-aminobenzoyl chromophore is still red-shifted compared with the free chromophore, but only to $\approx 354 \mathrm{~nm}$, i.e., some $12 \mathrm{~nm}$ less than with native pMCADH. The affinity of this ligand to 2'-deoxy-FAD-MCADH is somewhat higher than native pMCADH (Table 3).

The Structure of 2'-Deoxy-FAD-MCADH. The overall three-dimensional structure of $2^{\prime}$-deoxy-FAD-MCADH is the same as that of pMCADH. Figure 6 shows a $2 F_{\mathrm{o}}-F_{\mathrm{c}}$ difference Fourier map, clearly indicating that the enzymebound flavin analogue is $2^{\prime}$-deoxy-FAD. Furthermore, replacing the enzyme-bound FAD with $2^{\prime}$-deoxy-FAD does not change the polypeptide folding of the enzyme. The rootmean-square (rms) deviation between the main chain atoms of $2^{\prime}$-deoxy-FAD-MCADH and MCADH is $0.23 \AA$, and the corresponding value between $\mathrm{MCADH} / \mathrm{C}_{8} \mathrm{CoA}$ and $2^{\prime}$-deoxyFAD-MCADH $/ \mathrm{C}_{8} \mathrm{CoA}$ is $0.32 \AA$. These values are close to the values observed between two monomers in the pMCADH structures, $0.21 \AA$, and among four monomers in the human MCADH structures, $0.27 \AA$ (54). Therefore, both the free and ligand-bound structures of 2'-deoxy-FADMCADH are essentially the same as those of wild-type $\mathrm{MCADH}$ and its complex with $\mathrm{C}_{8} \mathrm{CoA}$, respectively. The occupancy of the $\mathrm{C}_{8} \mathrm{CoA}$ in the 2'-deoxy-FAD enzyme complex is estimated to be 0.55 to 0.60 , compared with 0.85 to 0.90 for the normal FAD enzyme complex, indicating that the substrate binds to the 2'-deoxy-FAD enzyme somewhat less tightly than to the normal enzyme. As in the pMCADH structure, the active site of 2'-deoxy-FAD-MCADH is occupied with water molecules, although not as well defined as in the normal pig enzyme structure (26). It is noteworthy that a water molecule is located at the position where the carbonyl oxygen atom of the substrate would occupy and is making a hydrogen bond with the amide nitrogen of Glu376. However, the occupancy of the water molecule is lower than that seen in the pMCADH structure, where the water molecule makes two hydrogen bonds, one to 2'-OH of the flavin and the other to the amide nitrogen of Glu376.

Substrate/Product Binds to the Active Site Cavity of 2'Deoxy-FAD-MCADH in the Same Manner as the One Observed in Normal MCADH. $\mathrm{C}_{8} \mathrm{CoA}$ binds to the active site; however, at this resolution it cannot be determined whether the bound ligand is $\mathrm{C}_{8} \mathrm{CoA}$ (substrate) or octenoyl$\mathrm{CoA}$ (product). The carbonyl group of the ligand is hydrogen bonded to the amide group of Glu376 (3.1 А), as in the wildtype enzyme (Figure 7). However, no other interactions are observed involving this carbonyl group. There is not enough room for any water molecules (or any other solvent molecules) to be present in the vicinity of the ribityl 2 -carbon atom in the active-site cavity. Figure 7 also shows a $2 F_{0}-$ $F_{\mathrm{c}}$ map showing the densities of the bound $\mathrm{C}_{8} \mathrm{CoA}$ found in the structure, along with some of the residues that form the active site pocket. The conformations of the residues in the active site are similar to those of the $\mathrm{MCADH} / \mathrm{C}_{8} \mathrm{CoA}$ complex. However, the conformation of the Glu376 side chain in the deoxy enzyme is similar to that found in the uncomplexed enzyme structures (both MCADH and 2'deoxy-FAD-MCADH), rather than the one found in the $\mathrm{MCADH} / \mathrm{C}_{8} \mathrm{CoA}$ structure (thin line, Figure 7).

\section{DISCUSSION}

The results of the present experiments are consistent with the three-dimensional structure in which the 2'-OH group, not the 3'-OH group, of the FAD ribityl side chain interacts with the carbonyl group of the thioester substrate, forming a tight hydrogen bond with a distance of $2.8 \AA$ (26). Furthermore, as seen in the three-dimensional structure, no water molecule (albeit a poor substitute) can take the role of the $2^{\prime}-\mathrm{OH}$ by bridging the ribityl chain (at either $3^{\prime}-\mathrm{OH}$ or $\left.4^{\prime}-\mathrm{OH}\right)$ and the carbonyl oxygen of the substrate. The properties of 3'-deoxy-FAD-MCADH compared with those of normal pMCADH demonstrate that the $3^{\prime}-\mathrm{OH}$ does not play any particular role in catalysis, nor in FAD or substrate binding to MCADH. Again, this is in full agreement with the three-dimensional structure that shows the $3^{\prime}-\mathrm{OH}$ group is not involved in any direct interaction with either FAD or the substrate, but is pointing toward Gly352-Gly353 of the neighboring monomer. MCADH is thus the first enzyme in which a direct catalytic role has been demonstrated for a functional group of the FAD cofactor other than the isoalloxazine ring. 

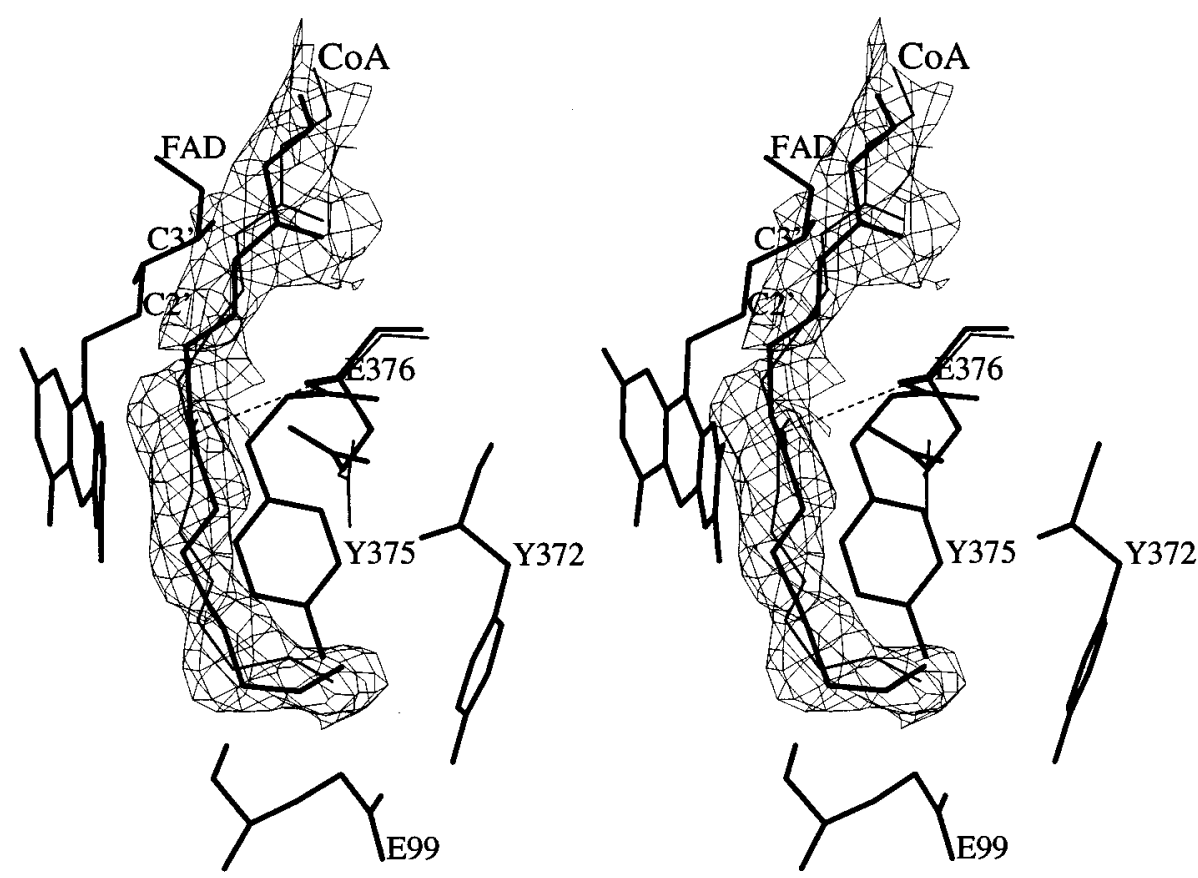

FIgURE 7: Stereodiagram of a model of $\mathrm{C}_{8} \mathrm{CoA}$ fitted in the final $2 F_{\mathrm{o}}-F_{\mathrm{c}}$ map of $2^{\prime}$-deoxy-FAD-MCADH complexed with $\mathrm{C}_{8} \mathrm{CoA}_{\mathrm{A}}$ The electron density was contoured at the 0.9-s level. The ligand $\left(\mathrm{C}_{8} \mathrm{CoA}\right), \mathrm{FAD}$ and active site residues from MCADH/C $\mathrm{C}_{8} \mathrm{CoA}($ thin lines) and $2^{\prime}$-deoxy-FAD-MCADH/ $\mathrm{C}_{8} \mathrm{CoA}$ (thick lines) are superimposed. For clarity, only $\mathrm{C}_{8} \mathrm{CoA}_{\mathrm{A}}$ and Glu376 of the $\mathrm{MCADH} / \mathrm{C}_{8} \mathrm{CoA}$ structure are shown. Other residues have essentially the same conformations as those of the $2^{\prime}$-deoxy-FAD-MCADH/ $\mathrm{C}_{8} \mathrm{CoA}$ complex. The conformation of the Glu376 side chain in the 2'-deoxy-FAD structure is similar to that of the native uncomplexed structure.

The main point emerging from this study is the large difference in the rate of substrate dehydrogenation between normal MCADH and 2'-deoxy-FAD-MCADH. This corresponds to a factor $\approx 1.5 \times 10^{7}$, which can be translated to a difference in activation energies $\Delta \Delta G^{\ddagger}$ for $\mathrm{C}_{8} \mathrm{CoA}$ dehydrogenation $\approx 38 \mathrm{~kJ} \mathrm{~mol}^{-1}$. It should be recalled that upon binding to hwtMCADH, 4NPA-CoA and $3 \mathrm{~S}-\mathrm{C}_{8} \mathrm{CoA}$ experience a shift of their microscopic $\alpha \mathrm{C}-\mathrm{H} \mathrm{p} K$ from $\approx 13.6$ and $\approx 16$, respectively, to $\approx 5(14)$. Based on this, it has been deduced that the corresponding shift with the substrate $\mathrm{C}_{8}$ CoA should be of the order of $\geq 10 \mathrm{p} K$ units (14). With 2'deoxy-FAD-MCADH, the decrease of the microscopic $\mathrm{p} K$ values of $\alpha \mathrm{C}-\mathrm{H}$ of the same, bound ligands is much smaller, as expected. The $\alpha \mathrm{C}-\mathrm{H} \mathrm{pK}$ of bound $3 \mathrm{~S}-\mathrm{C}_{8} \mathrm{CoA}$ can only be estimated to be $\approx 11$ with a considerable error range (Figure 2). Even if this number is a mere approximation, this would correspond to a shift of $\approx 5 \mathrm{p} K$ units, i.e., to an energetic equivalent of $\approx 30 \mathrm{~kJ} \mathrm{~mol}^{-1}$. If $3 \mathrm{~S}-\mathrm{C}_{8} \mathrm{CoA}$ and $\mathrm{C}_{8^{-}}$ $\mathrm{CoA}$ are assumed to bind in a thermodynamically equivalent fashion, it can be concluded that the $2^{\prime}-\mathrm{OH}$ hydrogen bond serves not only to promote $\alpha \mathrm{C}-\mathrm{H}$ deprotonation, but, together with Glu376-NH, probably also to attain proper substrate orientation for catalysis (26).

The $K_{\mathrm{d}}$ values of ligands for binding to MCADH compared with 2'-deoxy-FAD-MCADH (cf. Table 3) also yield information on the interaction at the active centers. Thus the affinities of the six ligands studied do not vary to large extents, with two exceptions, that of 3-ketooctanoyl-CoA and that of $3 \mathrm{~S}-\mathrm{C}_{8} \mathrm{CoA}$. 3-Ketooctanoyl-CoA is the only ligand that interacts in its anionic form with the active site of 2'deoxy-FAD-MCADH, and the only one for which a $K_{\mathrm{d}}$ could be estimated. The difference in binding energy between $2^{\prime}$ deoxy-FAD-MCADH and pMCADH $\left(\approx 10 \mathrm{~kJ} \mathrm{~mol}^{-1}\right)$, corresponds to the strength of a normal hydrogen bond, and this reflects mainly the forces involved in the stabilization of negative charge of the ligand. This would be in line with the concept of less efficient ground-state stabilization compared with that occurring in the transition state, in which a negative charge develops and strengthens the $\mathrm{H}$-bonds in a hydrophobic environment, as discussed below. In the charge-transfer complex between 3-ketooctanoyl-CoA and $\mathrm{MCADH}$, a strong hydrogen bond to the thioester-carbonyl group has recently been implied by IR/Raman spectroscopy. The energetic content of a hydrogen bond agrees with the present data (23). For the binding of neutral $3 \mathrm{~S}-\mathrm{C}_{8} \mathrm{CoA}$ to yield anionic ligand in the hwtMCADH complex, it is difficult to estimate the binding energy, because the observed $K_{\mathrm{d}}$ for binding to hwtMCADH is the product of binding as such and of the involved ionization (ratio of the microscopic $\mathrm{p} K$ values of $\alpha \mathrm{C}-\mathrm{H}$ and Glu376-COO${ }^{-}$) (14). The behavior of octyl-CoA, a CoA thioether lacking the thioester carbonyl group, is also of interest. As expected, with this analogue the presence of the $2^{\prime}-\mathrm{OH}$ has little effect on binding, as shown in Table 2.

Interpretations of the binding behavior of $4 \mathrm{AB}-\mathrm{CoA}$ require due caution because, in analogy with 4NPA-CoA (14), one could expect the $p-\mathrm{NH}_{2}$ function of this ligand to interact with Glu99-COO ${ }^{-}$, as shown in Scheme 4 for 4NPA$\mathrm{CoA}$ (structure B) and as demonstrated elsewhere (14). 4AB$\mathrm{CoA}$, however, is one methylene group shorter than 4NPACoA. Therefore, it is not surprising that $4 \mathrm{AB}-\mathrm{CoA}$ is not interacting directly with the carboxylate of Glu99. Thus with Glu99Gly-MCADH and 4AB-CoA the same spectral effects are observed as with native MCADH (Figure 5). In MCADH, the $\approx 50$-nm shift of the 4-aminobenzoyl chromophore $\pi-\pi^{*}$ transition (from $\approx 315$ to $\approx 365 \mathrm{~nm}$, Figure 5) is therefore attributed to a strong polarization as shown in Scheme 4, C, and as observed with other ligands derived from product (18). With 2'-deoxy-FAD-MCADH, the corresponding red shift is $\approx 40 \mathrm{~nm}$ and the difference can thus be attributed to the 
absence of the $2^{\prime}-\mathrm{OH}-$ thioester hydrogen bond. Intuitively one would expect the absence of the $2^{\prime}-\mathrm{OH}$ interaction to result in a shift smaller than the observed $40 \mathrm{~nm}$, if the two $\mathrm{H}$-bonds were to contribute equally to the polarization. These observations suggest that a single $\mathrm{H}$-bond is sufficient for inducing polarization with this analogue.

In conclusion, the present results provide the first example of a direct involvement in catalysis of the ribityl group of the flavin coenzyme. These results are the basis of an estimation of the energetic contribution to catalysis by MCADH of the H-bond(s) provided by the 2'-OH (and, to a lesser extent, by Glu376N-H), via (mainly) the acidification of the $\alpha \mathrm{C}-\mathrm{H}$ of the ligand. Because the contributions of the two single $\mathrm{H}$-bonds are approximately equivalent, the overall effect results from the additive individual contributions. Taking this and recent estimates of the microscopic $\mathrm{p} K_{\mathrm{a}}$ values of Glu376-COOH in free (14) and ligand bound enzyme (52), together with the $\mathrm{p} K$ shift in the $\alpha \mathrm{C}-\mathrm{H}$ of the ligand upon binding (14), a semiquantitative picture of MCADH catalysis can be drawn in which several basic enzymological concepts are realized. An important concept in proton transfer is the matching of the $\mathrm{p} K$ values of acceptor and donor (19). A second one is the increase of hydrogen bond strength induced by decreasing the dielectric constant and concomitant formation of transient charges (16). It appears that this aspect of MCADH is an example for what was suggested recently by Shan and Herschlag $(13,55)$. A third concept is the combined effect of H-bonds, dielectric changes, and charge rearrangements on the redox potentials of substrate and flavin (i.e., the redox partners, 43).

\section{ACKNOWLEDGMENT}

We thank M. Sappelt for skillful technical assistance and R. Paschke for crystallizing 2'-deoxy-FAD-MCADH.

\section{REFERENCES}

1. Crane, F. L., Mii, S., Hauge, J. G., Green, D. E., and Beinert, H. (1956) J. Biol. Chem. 218, 701-716.

2. Beinert, H. (1963) in The Enzymes (Boyer, P. D., Lardy, H., and Myrbäck, K., Eds.) 2nd ed., Vol. 7, pp 447-476, Academic Press, New York.

3. Engel, P. C. (1992) in Chemistry and Biochemistry of Flavoenzymes (Müller, F., Ed.) Vol. III, pp 597-655, CRC Press, Boca Raton, FL.

4. Ghisla, S., Engst, S., Vock, P., Kieweg, V., Bross, P., Nandy, A., Rasched, I., and Strauss, A. (1994) in Flavins and Flavoproteins 1993. Proceedings of the Eleventh International Symposium, Nagoya (Yagi, K. Ed.) pp 283-292, Walter DeGruyter \& Co., Berlin.

5. Thorpe, C., and Kim, J. J. (1995) FASEB J. 9, 718-725.

6. Rowland, P., Larsen, S., Nielsen, F. S., Björnberg, O., and Jensen, K. F. (1997) in Flavins and Flavoproteins 1996. Proceedings of the Twelfth International Symposium, Calgary (Stevenson, K. J., Massey, V., and Williams, C. H., Jr., Eds.) pp 927-930, University of Calgary Press, Calgary, Alberta, Canada.

7. Fendrich, G., and Abeles, R. H. (1982) Biochemistry 21, 6685-6695.

8. Powell, P. J., and Thorpe, C. (1988) Biochemistry 27, 80228028.

9. Bross, P., Engst, S., Strauss, A. W., Kelly, D. P., Rasched, I., and Ghisla, S. (1990) J. Biol. Chem. 265, 7116-7119.

10. Ghisla, S., Thorpe, C., and Massey, V. (1984) Biochemistry $23,3154-3161$.
11. Pohl, B., Raichle, T., and Ghisla, S. (1986) Eur. J. Biochem. $160,109-115$.

12. Gerlt, J. A., and Gassman, P. G. (1993) J. Am. Chem. Soc. $115,11552-11568$.

13. Shan, S., Loh, S., and Herschlag, D. (1996) Science 272, 97101

14. Vock, P., Engst, S., Eder, M., and Ghisla, S. (1998) Biochemistry $37,1848-1860$.

15. Ghisla, S., Braunwarth, A., and Vock, P. (1997) in Flavins and Flavoproteins 1996. Proceedings of the Twelfth International Symposium, Calgary (Stevenson, K. J., Massey, V., and Williams, C. H., Jr., Eds.) pp 629-632, University of Calgary Press, Calgary, Alberta, Canada.

16. Rudik, I., Ghisla, S., and Thorpe, C. (1998) Biochemistry, in press.

17. Amyes, T. L., and Richard, J. P. (1992) J. Am. Chem. Soc. 114, 10297-10302.

18. Trievel, R. C., Wang, R., Anderson, V. E., and Thorpe, C. (1995) Biochemistry 34, 8597-8605.

19. Gilbert, H. F., Lennox, B. J., Mossman, C. D., and Carle, W. C. (1981) J. Biol. Chem. 256, 7371-7377.

20. Lau, S.-M., Brantley, R. K., and Thorpe, C. (1988) Biochemistry 27, 5089-5095.

21. Engst, S., and Ghisla, S. (1991) in Flavins and Flavoproteins, Proceedings of the Tenth International Symposium, Como (Curti, B., Ronchi, S., and Zanetti, G., Eds.) pp 311-314, W. de Gruyter, Berlin.

22. Johnson, J. K., Wang, Z. X., and Srivastava, D. K., (1992) Biochemistry 31, 10564-10575.

23. Hazekawa, I., Nishina, Y., Sato, K., Shichiri, M., and Shiga, K., J. (1995) J. Biochem. 118, 900-910.

24. Nishina, Y., Sato, K., Shiga, K., Fujii, S., Kuroda, K., and Miura, R. (1992) J. Biochem. (Tokyo) 111, 699-706.

25. Nishina, Y., Sato, K., Hazekawa, I., and Shiga, K., (1995) J. Biochem. 117, 800-808.

26. Kim, J. J. P., Wang, M., and Paschke, R. (1993) Proc. Natl. Acad. Sci. U.S.A. 90, 7523-7527.

27. Raichle, T. (1981) Ph.D. Thesis, University of Konstanz, Konstanz, Germany.

28. Langkau, B., (1994) Ph.D. Thesis, University of Konstanz, Konstanz, Germany.

29. Al-Arif, A., and Blecher, M. (1969) J. Lipid Res. 10, 344345.

30. Goldmann, P., and Vagelos, P. R. (1961) J. Biol. Chem. 236, 2620-2623.

31. Murthy, Y. V. S, and Massey, V. (1995) J. Biol. Chem. 270, $28586-28594$.

32. Kasai, S., Sugimoto, K., Miura, R. Yamano, T., and Matsui, K. (1983) J. Biochem. 93, 397-402.

33. Korte, F., and Ludwig, G. (1958) Ann. Chem. 615, 94-99.

34. Tischler, M., Pfister, K., Babson, R. D., Ladenburg, K., and Fleming, A. J. (1947) J. Am. Chem. Soc. 69, 1487-1492.

35. Mayer, E. J., and Thorpe, C. (1981) Anal. Biochem. 116, $227-$ 229.

36. Freund, K., Mizzer, J., Dick, W., and Thorpe, C. (1985) Biochemistry 24, 5996-6002.

37. Thorpe, C., Matthews, R. G., and Williams, C. H. (1979) Biochemistry 18, 331-337.

38. McPherson, A. (1990) Eur. J. Biochem. 189, 1-23.

39. Otwinowski, Z., and Minor, W. (1996) Methods Enzymol. 276, 307-326.

40. Brunger, A. T. (1992) X-PLOR: A System for X-ray Crystallography and NMR, Version 3.1; Yale University Press, New Haven, CT.

41. Cambillau, C., and Roussel, A. (1993) TURBO-FRODO: Manual for a Molecular Graphics Program for Silicon Graphics, version 4.2, Biographics, Marseille, France.

42. Lehman, T. C., Hale, D. E., Bhala, A., and Thorpe, C. (1990) Anal. Biochem. 186, 280-284.

43. Mancini-Samuelson, G., Kieweg, V., Sabaj, K. M., Ghisla, S., and Stankovich, M. T. (1998) Biochemistry 37, 1460514612.

44. Johnson, B. D., and Stankovich, M. T. (1993) Biochemistry 32, 10779-10785. 
45. Massey, V. (1991) in Flavins and Flavoproteins 1990, Proceedings of the Tenth International Symposium, Como (Curti, B., Ronchi, S., and Zanetti, G. Eds.) pp 59-66, W. DeGruyter, Berlin.

46. Schopfer, L. M., Massey, V., Ghisla, S., and Thorpe, C. (1988) Biochemistry 27, 6599-6611.

47. Thorpe, C., Ciardelli, T. L., Stewart, C. J., and Wieland, T. (1981) Eur. J. Biochem. 118, 279-282.

48. Nandy, A., Kieweg, V., Kräutle, F., Vock, P., Küchler, B., Bross, P., Kim, J.-J. P., Rasched, I., and Ghisla, S. (1996) Biochemistry 35, 12402-12411.

49. Thorpe, C., and Massey, V. (1983) Biochemistry 22, $2972-$ 2978.

50. Lau, S.-M., and Thorpe, C. (1988) Arch. Biochem. Biophys. 262, 293-297.
51. Strickland, S., Palmer, G., and Massey, V.(1975) J. Biol. Chem. 250, 4048-4052.

52. Kumar, N. R., and Srivastava, D. K. (1994) Biochemistry 33, 8833-8841.

53. Powell, P. J., Lau, S.-M., Killian, D., and Thorpe, C. (1987) Biochemistry 26, 3704-3710.

54. Lee, H.-J. K., Wang, M., Paschke, R., Nandy, A., Ghisla, S., and Kim, J. J. (1996) Biochemistry 35, 1241212420 .

55. Shan, S., and Herschlag, D. (1996) Proc. Natl. Acad. Sci. U.S.A. 93, 14474-14479. 